\title{
Relações entre práticas de espiritualidade e valores organizacionais sob a percepção de jovens trabalhadores brasileiros
}

\author{
Relationships between Spirituality and practice organizational values under the \\ perception of young Brazilian workers
}

\author{
Elisângela Julião ${ }^{1}$ \\ Jair Nascimento-Santos ${ }^{2}$ \\ Kely Cesar Martins Paiva ${ }^{3}$
}

\begin{abstract}
Resumo
Este artigo aborda a forma como a espiritualidade tem adentrado as organizações com o objetivo de humanizar os ambientes laborais e reduzir as mazelas ocasionadas pela racionalidade exacerbada imposta pela industrialização através do trabalho rotineiro, fragmentado e repetitivo. Sendo assim, visa-se verificar as relações entre as práticas de espiritualidade e os valores organizacionais, questionando-se acerca de: Como as práticas de espiritualidade se relacionam com os valores organizacionais na percepção de jovens trabalhadores? De cunho quantitativo, a matriz de correlações e as estatísticas descritivas foram utilizadas para alcançar o objetivo do estudo. Para coletar os dados, aplicou-se pela internet um questionário estruturado com jovens pertencentes a instituições brasileiras que trabalham com a atividade de aprendizagem e capacitação de jovens com idade entre 18 e 24 anos. Dos questionários aplicados, a pesquisa obteve um retorno de 406 questionários válidos. Os resultados apontaram que os jovens percebem que as práticas de espiritualidade (diminuição da carga de trabalho, valorização do funcionário e exercício da espiritualidade) possuem uma forte associação com os valores organizacionais (bem-estar, autonomia e preocupação com a coletividade), apontando ainda suspeitas de que a prática de espiritualidade seja preditora da percepção dos indivíduos acerca das metas dos valores organizacionais.
\end{abstract}

Palavras-chave: Espiritualidade. Valores Organizacionais. Jovem Trabalhador.

\begin{abstract}
This article discusses how spirituality has entered the organisations with the aim of humanizing working environments to reduce the sufferings occasioned by exacerbated rationality imposed by industrialization through the routine work, fragmented and repetitive. Therefore, the aim is to verify the relationship between spirituality and practices the organizational values, questioning itself about: spirituality practices relate to the organizational values in the perception of young workers? Quantitative measures, the matrix of correlations and descriptive statistics were used to achieve the objective of the study. To collect the data, structured questionnaire was applied by internet, with young people belonging to institutions that work with the activity of learning and capacity building of young people aged between 18 and 24 years, in Brazil. Of the questionnaires applied, research obtained a return of 406 valid questionnaires. The results showed that young people realize that the practice of spirituality (decreased workload, employee appreciation and practice of spirituality) have a strong association with the organizational values (welfare, autonomy and concern with the collective), pointing out that yet the practice of spirituality is predictive of the perception of individuals about the goals of organizational values.
\end{abstract}

Keywords: Spirituality. Organizational Values. Young Worker.

Mestre em administração de Empresas; Administradora; Professora de cursos de pós-graduação; Consultora organizacional. Participante dos núcleos de estudos em Gestão de Pessoas e em Estudos Organizacionais do CRA. Brasil. Email: elisangela_juliao@yahoo.com.br ORCID: http://orcid.org/0000-0001-5101-2878

2 Doutor em Administração pela Universidade Federal de Minas Gerais e École dês Hautes Études Commerciales de Montréal. Coordenador da Divisão Gestão de Pessoas e Relações de Trabalho da Anpad. Brasil. Afiliação: Unifacs - Universidade Salvador/ UNEB - Universidade do estado da Bahia Lattes: http://lattes.cnpq.br/5715434041307147 Email: jair.santos@unifacs.br

3 Doutora, Mestre e Bacharel em Administração. Professora (Adjunto II) e Pesquisadora, Departamento de Ciências Administrativas (CAD), Centro de Pós-graduação e Pesquisa em Administração (CEPEAD), Faculdade de Ciências Econômicas (FACE), Universidade Federal de Minas Gerais (UFMG). Brasil. Afiliação: UFMG. Lattes: http://lattes.cnpq.br/0189644589413057 Email: kelypaiva@face.ufmg.br 


\section{Introdução}

O trabalho é reconhecido como algo inerente ao indivíduo desde os tempos mais remotos da humanidade. A priori, teve uma conotação de sobrevivência, mas, ao longo da história, o trabalho foi mudando o seu significado e tornando-se algo sem sentido para o seu executor, principalmente em virtude de suas tarefas passarem a obedecer uma lógica pautada na extrema racionalidade em prol da maximização dos lucros para as organizações e maior degradação para os empregados, causando-lhes uma série de mazelas físicas, sociais e psíquicas, e transformando o local de trabalho em um ambiente de sofrimento e exclusão da condição humana, em que, portanto, a subjetividade do indivíduo tem sido negligenciada (CHANLAT, 1996; SENNET, 2009; VERGARA; MOURA, 2012).

Assim sendo, para tentar resgatar o respeito às necessidades emocionais e espirituais do trabalhador, sem deixar de lado a sua racionalidade, busca-se reconhecer que o trabalhador possui uma vida interior, a qual precisa ser nutrida a partir de um trabalho com significado e que the expresse senso de pertencimento à comunidade (ASHMOS; DUCHON, 2000), a partir da implantação da espiritualidade organizacional como meio de humanizar os ambientes laborais, uma vez que, sem ela, o futuro da organização pode ser curto (MITROFF; DENTON, 1999). Desse modo, para implantar a espiritualidade nas organizações, fazse necessária uma mudança nos valores organizacionais, haja vista que eles são a representação das percepções dos trabalhadores acerca das características atinentes aos princípios e crenças da organização (OLIVEIRA; TAMAYO, 2004; TAMAYO; GONDIM, 1996;).

Dito isso, uma vez que a inserção da espiritualidade nas organizações pode impactar nos valores organizacionais, questiona-se: Como as práticas de espiritualidade se relacionam com os valores organizacionais na percepção de jovens trabalhadores? Para tanto, este estudo objetivou compreender as relações entre as práticas de espiritualidade e os valores organizacionais, considerando que a espiritualidade organizacional tende a favorecer o desenvolvimento das potencialidades racionais e espirituais do indivíduo, com vistas a dar sentido ao trabalho, enquanto que os valores organizacionais representam a percepção dos funcionários acerca da organização.

A relevância do estudo antepara-se em várias frentes, como: ampliar o arcabouço literário sobre os aspectos que permeiam a trajetória laboral do jovem brasileiro, devido às poucas pesquisas nessa direção e por considerar que estudar a juventude pode resultar em soluções muito significativas para a sociedade (OIT, 2009); alargar os estudos da espiritualidade no cenário nacional, haja vista que, no âmbito internacional, as pesquisas estão avançadas, enquanto que, no Brasil, ainda avançam, conforme buscas realizadas nos repositórios digitais (ANPAD, Scielo, SPELL); dar continuidade aos estudos sobre valores organizacionais a fim de acompanhar as mudanças da sociedade; e pelo ineditismo da correlação entre a espiritualidade e os valores organizacionais na percepção de jovens trabalhadores brasileiros, abrindo, portanto, uma possibilidade de acrescentar produções à literatura.

\section{Revisão de literatura}

\subsection{Trabalho: rotinização e a consequente perda do seu sentido}

O trabalho, na sociedade moderna, tem sido tratado como instrumento de motivação, com implicação na satisfação e produtividade dos trabalhadores, assumindo aspecto relevante na vida das pessoas ao ponto de considerarem a possibilidade de continuar trabalhando, ainda que não tenham mais a necessidade financeira. $O$ trabalho converteu-se em: a) ter um objetivo de vida; b) estabelecer vínculos com outras pessoas; c) ter "o que fazer"; e d) evitar o tédio. Logo, está além da necessidade da dignidade humana, tornando-se a sua fundação, isso porque, para algumas pessoas, o desejo de significado e realização no trabalho ultrapassa o desejo da obtenção do dinheiro ou do tempo livre, assumindo um papel maior que uma simples relação salarial (DEJOURS, 2004; FRY, 2003; MORIN, 2001; PAUCHANT, 2000).

Por fazer parte dos primórdios da humanidade, é natural que o indivíduo busque no trabalho um significado que responda além da consecução de suas necessidades de sobrevivência, realização, pertencimento, sublimação e outras. Por conta disso, o trabalho assumiu características diferentes ao 
longo dos tempos, tais como: intelectual (elite) ou braçal (escravos) no período $\mathrm{V}$ a.C.; castigo dos deuses ("trabalho de Sísifo") na mitologia grega; vergonhoso (escravidão); ascético, promotor da dignidade humana, na idade média; e mercadoria, por intermédio da "força de trabalho", no renascimento (FARIAS; SCHMITT, 2004; ORNELLAS; MONTEIRO,2006;RAMOS, 2008).

É na condição de mercadoria que o trabalho passa a ser alvo de alterações na forma como é executado, buscando maior eficiência a fim de auferir maiores lucros para as organizações. Nesse sentido, Taylor propõe a cientificação do trabalho, ao passo que cria o "sistema funcional da organização administrativa do trabalho industrial", baseado no planejamento e execução, dando partida a trabalhos subsequentes como: a) os gráficos de controle de produção do trabalho (Gantt); b) a régua de cálculo para fadiga do trabalhador (Barth); c) os processos de cronometragem do trabalho (Thompson); d) o rendimento do trabalho (Emerson); e e) a cientificação dos estudos dos movimentos (Gilbreths), dentre outros (RAMOS, 2008).

Nessa nova forma de trabalhar imposta pelo capitalismo do século XVIII, seriada e com rigidez burocrática, se desenvolveram anomalias que causaram conflitos entre os trabalhadores e as organizações, como: ausência de direitos trabalhistas; exclusão integral do proletariado do processo produtivo; submissão de mulheres e crianças a condições inumanas de trabalho; salários insuficientes, etc. (ORNELLAS; MONTEIRO, 2006).

Dos conflitos gerados acerca da rotina e burocracia rígida atribuída ao trabalho, surgiram defensores e opositores dessa nova concepção. Denis Diderot, filósofo francês, defendia o trabalho rotineiro e burocrático, considerando-o como algo fraterno, sereno e necessário para a aprendizagem, mas para Adam Smith, filósofo e economista escocês, essa era uma visão utópica, pois esse tipo de trabalho possuía superficialidade e não produzia qualquer fraternidade ou serenidade, mas o embrutecimento, a estupidez e a ignorância no homem à medida que limitava o indivíduo a ficar "a vida inteira realizando umas poucas operações simples", que causavam-Ihe tédio e descontrole por seus esforços e tempo, significando para o trabalhador uma "morte espiritual" (SENNETT, 2009).

Se, por um lado, as organizações clamavam por maior eficiência nas tarefas para a obtenção de maiores lucros, por outro lado, surgiam patronos da condição humana nas organizações, como o Elton Mayo,psicólogo industrial, que, através do seu experimento em Hawtorne, afirmou que ao humanizar as relações de trabalho a produtividade aumentaria, mas o tédio e a insatisfação oriundos da rotinização das tarefas não seriam eliminados (SENNET, 2009). Para tentar sanar o problema do tédio e da insatisfação no trabalho, Aktouf (2010) sugere a desalienação do trabalho através da participação do indivíduo na criação das tarefas, compreendendo-as de forma clara e completa, de modo a dar significado e vida ao trabalho, tornando-o mais do que instrumento para o alcance da sobrevivência.

Dito isso, a partir da compreensão de que o trabalho é fator importante para organizações e funcionários, enfatiza-se a necessidade de encontrar formas de realizá-lo de modo a satisfazer a ambos. Um caminho nessa direção pode ser o da valorização da subjetividade do indivíduo nas organizações.

\subsection{Subjetividade: a dimensão esquecida nas organizações}

Enxergar todas as dimensões que permeiam o trabalhador é condição sine qua non para garantir a maior eficiência nas organizações contemporâneas, pois o indivíduo é integral, sendo objeto e sujeito de sua ciência. As organizações têm feito muitos investimentos em tecnologia, o que não é suficiente, pois além dos avanços tecnológicos, é necessário também o avanço dos valores humanos. A produção exacerbadamente racional reduz a subjetividade, a dimensão emotiva, a criatividade e a estética da tarefa laboral, sacrificando a condição humana nas relações do trabalho em prol da rentabilidade e da competitividade (CHANLAT, 1996; DE MASI, 2001).

Com a finalidade de atender às demandas das organizações, os trabalhadores são controlados de forma objetiva (salários, manuais, etc.) ou de uma maneira mais sutil, que ultrapassa a condição física do trabalhador, alcançando a sua subjetividade através dos desejos e necessidades de pertencimento, de filiação, de reconhecimento, de afeto e de realização (DEJOURS, 2004; FARIA; SCHMITT, 2004). No entanto, esse controle pode gerar danos para ambas as partes: a organização pode perder em criatividade 
e inovação nas tarefas; e o trabalhador poderá ter sua liberdade cerceada por conta do vínculo estabelecido com a organização, perdendo a autonomia dos seus saberes e valores, sendo manipulado e sutilmente envolvido, tendo sua subjetividade sequestrada (REGATIERI et al., 2010).

\subsection{Espiritualidade nas organizações}

Até o início do século $X X$, é tido como inteligente o indivíduo possuidor de habilidades quantitativas. Na década de 1990, contudo, Daniel Goleman expande esse entendimento ao afirmar que a inteligência não se resume apenas ao campo da razão, uma vez que a emoção impacta fortemente o intelectivo, afetando a eficácia dos pensamentos e ações - trata-se da inteligência emocional. Dilatando a possibilidade de outras formas de inteligência humana, o novo milênio adentra com uma inteligência focada em um contexto ainda mais amplo, a inteligência espiritual, considerada a base para as demais inteligências do indivíduo (ZOHAR, MARSHAL, 2001).

Na seara das organizações, a espiritualidade é a forma contemporânea da verdadeira grandeza na constituição de uma civilização, representando o mais alto grau de enraizamento do homem no universo e possibilitando que se viva de forma integrada, em harmonia com a natureza e o espírito. Como consequência, há uma reinterpretação do conceito de trabalho à medida que se reconhece que os trabalhadores têm uma vida interior, que necessita ser nutrida por um trabalho que possua significado e senso comunitário (ASHMOS; DUCHON, 2000;LEFEBVRE, 2000; MITROFF,2000;PAUCHANT, 2000; WEIL,1949). Quando evidenciada na cultura organizacional, a espiritualidade surge como uma estrutura de valores organizacionais, que permite ao empregado experimentar a transcendência e o sentido de conexão, plenitude e alegria na realização do trabalho (GIACALONE; JURKIEWICZ, 2003 apud JURKIEWICZ; GIACALONE, 2003). Portanto, a espiritualidade no local de trabalho se expressa quando

os seres humanos são sensíveis a temas como: a justiça, a confiança, o tratamento respeitador e digno, a possibilidade de obterem no trabalho significado para a vida, as oportunidades de desenvolverem o seu potencial e se realizarem como seres emocional e intelectualmente válidos, as relações interpessoais de cooperação e ajuda, a possibilidade de se sentirem insertos em comunidades humanas que lhes permitem satisfazer necessidades de afiliação e de pertença. (REGO; SOUTO; CUNHA, 2005, p.5).

A espiritualidade não é o mesmo que religião, pois a espiritualidade é liberal e menos formal, enquanto a religião é burocrática e formal. Porém, apesar das diferenças, a religião embasou muitas das decisões éticas relacionadas ao trabalho e à espiritualidade (LEFEBVRE, 2000; MITROFF, 2000;).

Para melhor entendimento da espiritualidade nas organizações, pode-se representá-la em cinco dimensões: a) sentido de comunidade na equipe, que designa a interação entre pessoas e a necessidade da vida em comunidade; b) alinhamento do indivíduo com os valores da organização, que representa "compatibilidade dos valores e da vida interior do indivíduo com os valores da organização"; c) sentido de préstimo à comunidade (trabalho com significado), que resulta no profundo senso de significado e propósito em seu trabalho, implicando em importantes valores de vida do indivíduo, representando utilidade para a comunidade; d) alegria no trabalho, que se relaciona à satisfação e ao prazer no trabalho; e) oportunidades para a vida interior, que representa o respeito da organização quanto à vida interior do indivíduo, seus valores espirituais (REGO; CUNHA; SOUTO, 2005).

Estudos apontam que a implantação da espiritualidade nas organizações induz melhorias na saúde do trabalhador, maior bem-estar, aumento do comprometimento, redução de tournover, menor índice de absenteísmo, e maior produtividade (PANAHI, 2012). Logo, compreender o trabalhador na sua condição humana, dotado de necessidades biológicas, sociais, intelectuais, emocionais e espirituais, pode habilitar no indivíduo o espírito de comprometimento, significado, finalidade e satisfação nas suas tarefas (AJALA, 2013; VERGARA; MOURA,2012). Por outro lado, apesar dessas conjecturas otimistas apontadas acerca da espiritualidade, ainda há certa resistência em relação a ela, seja pela ausência de impactos demonstráveis para as organizações, seja em virtude de que as ciências de gestão estão impregnadas com o entendimento de que tudo o que não for quantificável deve ser desconsiderado (JURKIEWICZ; GIACALONE, 2003; 
REGO; CUNHA; SOUTO, 2005). Desse modo, embora os avanços científicos e tecnológicos sejam visíveis, não se vê intenção por parte das organizações em mudarem suas práticas na direção da espiritualidade, apesar do forte desejo dos trabalhadores em alcançar a satisfação no trabalho (VASCONCELOS, 2015).

\subsubsection{Práticas de espiritualidade nas organizações}

Praticar a espiritualidade no ambiente de trabalho implica vencer barreiras e superar desafios, como o preconceito em relação ao tema; o medo da perseguição; a ausência de modelos e ferramentas gerenciais; a dificuldade de conciliação entre os interesses econômicos e os princípios da espiritualidade; e a possibilidade de manipulação dos funcionários em prol dos interesses materialistas das organizações. Dito isso, entende-se o sentimento de entusiasmo e insegurança por parte dos gerentes ao se referirem a levar a espiritualidade para seus ambientes laborais (FRESHMAN, 1999; MITROFF, 2000; PAUCHANT, 2000).

Por esse motivo, aconselha-se que a inserção de práticas de espiritualidade nas organizações ocorra autenticamente, sem pretensões de lucros futuros, sendo, inclusive, inserida via programas de mudança organizacional, compondo o conjunto dos elementos dos objetivos profissionais, como também os feedbacks interno e externo e a maior participação dos trabalhadores (MILLIMAN, CZAPLEWISK, FERGUSON, 2003).

As práticas de espiritualidade versam também no sentido de valorizar o funcionário, possibilitando assim o aumento do desempenho individual. Isso ocorre a partir do momento em que o trabalhador enxerga no seu trabalho: significado para sua vida, um clima organizacional alegre e senso de comunidade. A partir dessa percepção, ele tende a ser mais produtivo, entregando-se de forma "física, mental, emocional e espiritual ao trabalho" (SOUTO; REGO, 2006). Quando a valorização se dá pela otimização racional do trabalho, há o impedimento da "realização plena da natureza humana", pois ali não se englobam todas as dimensões dos indivíduos (LAZZARESCHI, 2007).

Assim, para uma organização obter a gestão espiritualizada, ela necessita adotar pelo menos as seguintes práticas: a) exercício da espiritualidade; b) valorização do funcionário; c) diminuição da competição interna; e d) diminuição da carga de trabalho, conforme explanado no quadro 1 (BEZERRA; OLIVEIRA, 2007). 
Quadro 1 - Práticas de espiritualidade organizacional

\begin{tabular}{|c|c|c|}
\hline O que fazer? & Como fazer? & Quais ações? \\
\hline \multirow{5}{*}{$\begin{array}{l}\text { Exercício da } \\
\text { espiritualidade }\end{array}$} & \multirow{2}{*}{ Difundindo os conceitos } & Usar a comunicação interna para atingir a todos \\
\hline & & Promover palestras e cursos \\
\hline & \multirow{3}{*}{ Praticando os conceitos } & Incentivar ações como meditação \\
\hline & & Praticar a qualidade de vida \\
\hline & & Promover valores universais \\
\hline \multirow{6}{*}{$\begin{array}{l}\text { Valorização do } \\
\text { funcionário }\end{array}$} & \multirow{4}{*}{$\begin{array}{l}\text { Respeitar o funcionário } \\
\text { como pessoa }\end{array}$} & Tratamento digno \\
\hline & & Respeitar as necessidades emocionais \\
\hline & & Promover ações de reconhecimento do trabalhador \\
\hline & & Investir na motivação dos funcionários \\
\hline & \multirow{2}{*}{$\begin{array}{l}\text { Evitar a valorização } \\
\text { excessiva das metas }\end{array}$} & Valorizar os valores morais e não as metas alcançadas \\
\hline & & Reduzir as pressões para o alcance das metas \\
\hline \multirow{8}{*}{$\begin{array}{l}\text { Diminuição da } \\
\text { competição } \\
\text { interna }\end{array}$} & \multirow{2}{*}{$\begin{array}{l}\text { Evitar competições entre } \\
\text { os colegas }\end{array}$} & Valorizar aspectos da espiritualidade e não da competição \\
\hline & & Desestimular a competição interna \\
\hline & \multirow{3}{*}{$\begin{array}{l}\text { Promover atividades que } \\
\text { gerem maior amizade }\end{array}$} & Considerar o colega como irmão e amigo \\
\hline & & Programar encontros externos estimulando o companheirismo \\
\hline & & Promover a interação \\
\hline & \multirow{3}{*}{$\begin{array}{l}\text { Promover o respeito entre } \\
\text { os colegas }\end{array}$} & Estimular o respeito entre os colegas \\
\hline & & Mostrar a importância da consideração ao colega \\
\hline & & Treinar para evitar preconceitos e desrespeitos ao colega \\
\hline \multirow{4}{*}{$\begin{array}{l}\text { Diminuição } \\
\text { da carga de } \\
\text { trabalho }\end{array}$} & \multirow{2}{*}{$\begin{array}{l}\text { Reduzir o estresse e } \\
\text { cansaço }\end{array}$} & Rever a carga de trabalho que causa estresse e cansaço \\
\hline & & Diminuir a carga de trabalho exaustiva \\
\hline & \multirow{2}{*}{$\begin{array}{l}\text { Destinar tempo para ações } \\
\text { comunitárias e práticas da } \\
\text { espiritualidade }\end{array}$} & Disponibilizar tempo para ações comunitárias \\
\hline & & $\begin{array}{l}\text { Diminuir a carga de trabalho de modo a permitir o relaxamento } \\
\text { e a meditação }\end{array}$ \\
\hline
\end{tabular}

Fonte: Adaptado de Bezerra e Oliveira (2007)

Estudos comprovam que a espiritualidade tende a tornar o trabalhador comprometido, mas alcançar esse comprometimento não é uma tarefa fácil, haja vista o enraizamento nas organizações do paradigma capitalista calcado na máxima eficiência e altos lucros. O caminho sugerido é a mudança para um modelo de gestão humanizado, em que o funcionário seja visto em sua integralidade (BEZERRA; OLIVEIRA,2007; DIHIMAN;MARQUES,2010).

As oportunidades oriundas da implantação das práticas de espiritualidade podem ser vistas sob três perspectivas: a) recursos humanos; b) filosófica; e c) interpessoal. A primeira afirma que o foco é o bemestar do trabalhador através do aumento do moral, do aumento do comprometimento e da produção. e da diminuição do estresse e bournout no trabalho. Por seu turno, a perspectiva filosófica e existencialista explica o significado e propósito do trabalho, por intermédio do aumento da produtividade e desempenho. No que tange à perspectiva interpessoal e comunitária, ela promove nos trabalhadores um senso de comunidade e conexão, aumentando seu comprometimento, lealdade e eficácia (KARAKAS, 2010).

Além das oportunidades, algumas ameaças se apresentam na implantação da espiritualidade, representando aspectos que podem impactar negativamente a gestão espiritualizada nas organizações. Entre elas estão o perigo do proselitismo, a questão da compatibilidade de crenças ou interesses, o risco da espiritualidade no meio organizacional tornar-se mais um modismo gerencial e ser utilizada como ferramenta de manipulação dos trabalhadores, e a falta de legitimidade da espiritualidade no trabalho em teoria, pesquisa e prática (KARAKAS, 2010).

A presença do desemprego na sociedade faz com que a espiritualidade seja considerada, por alguns, como inadequada e utópica. Entretanto é o próprio desemprego uma das mazelas sociais ocasionadas pela 
ausência da espiritualidade no meio organizacional. Assim, o trabalho rotineiro e fragmentado, bem como os altos lucros e a exploração da mão de obra operária, tornam o ambiente laboral um local de sofrimento, desprazer e inóspito. A reversão desse quadro pode se dar com a adoção de práticas de espiritualidade a fim de favorecer a harmonia, a preconização da condição humana, e o respeito à vida interior do indivíduo (emoções, expectativase etc.)(VERGARA; MOURA, 2012).

Como a implantação das práticas de espiritualidade nas organizações precisa desenvolver programas densos de recursos humanos, com liderança consciente e cultura centrada nos valores (NEAL, 2013), as organizações mais propensas à implantação da espiritualidade são aquelas que possuem empresários motivados e com alto grau de paixão por seu negócio, a fim de considerar os espaços organizacionais como locais de divertimento, alegria e felicidade para seus funcionários, contribuindo para o bem-estar de todos a partir da redução dos níveis de estresse, conflito e absenteísmo (AJALA, 2013; KAUANUI et al., 2010).

\subsection{Valores organizacionais (VO)}

O valor é tido como um critério utilizado pelas pessoas para lhes dar um norte e avaliar ações, eventos e indivíduos. Quando organizados hierarquicamente, os valores podem referenciar modelos de comportamento desejáveis nas pessoas, orientando e expressando interesses (individuais, coletivos ou mistos) e motivações, além de caracterizar-se pela escolha de algo em desistência ou sacrifício de todo o resto. Nas organizações, os valores advêm da cultura e representam as percepções dos trabalhadores quanto ao ambiente laboral, bem como as formas de hierarquizar prioridades, representando cognições derivadas de três requisitos universais da condição humana referentes às necessidades: biológicas, de interação social para a sobrevivência e de bem-estar na convivência em grupo (FLEURY,1996; SCHWARTZ,1994; TAMAYO; SCHWARTZ, 1993).

As discussões acerca dos valores acontecem desde meados do século $X X$, abarcando áreas como a psicologia, a filosofia, a sociologia, a antropologia, entre outras. Observa-se que, no âmbito internacional, as pesquisas foram intensificadas na década de $1980 \mathrm{com}$ Shalom H. Schwartz (valores humanos), enquanto que, no nacional, as abordagens tomaram força uma década depois por Álvaro Tamayo e colaboradores (ALMEIDA; SOBRAL,2009; LOUBACK; TEIXEIRA; BIDO,2009). No Brasil, os estudos sobre valores organizacionais assumiram uma curva crescente entre o período de 1992 e 2014, saindo de 03 para 51 publicações no ano de 2014 (SCIELO, 2015), o que aponta o interesse da academia em tentar entender e compreender como os valores que circulam nas organizações intervêm no comportamento do trabalhador.

\subsubsection{Estudo de valores organizacionais}

Os estudos acerca dos valores organizacionais foram relegados em prol dos valores pessoais. Tal fato pode ter ocorrido em decorrência da dificuldade de se mensurar adequadamente as percepções dos trabalhadores na época (TAMAYO; GONDIM, 1996).

Os elementos que compõem a definição dos valores organizacionais são: a) o aspecto cognitivo (fundamento basilar, visto que estabelece as diretrizes comportamentais desejadas pela organização); b) o aspecto motivacional (designa o valor com base em algum indivíduo, que pode ser o dono ou o grupo, constituindo-se metas "mais ou menos conscientes"); c) a função dos valores (visa direcionar comportamento dos membros da organização); d) a hierarquização dos valores (que estabelece escalas de graus de valor baseadas no tempo, missão e objetivos da organização); e) os tipos de valores (individuais e terminais). A função maior dos VOs é a de criar nos indivíduos modelos mentais semelhantes no que tange ao funcionamento e missão da organização, de modo que esses valores sejam internalizados pelos pensamentos e ações, contribuindo para o controle coletivo, que pode resultar em prazer (flexibilização das normas) ou sofrimento (rigidez das normas) para os trabalhadores (TAMAYO, 1998; TAMAYO; GONDIM, 1996;TAMAYO; MENDES; PAZ,2000).

Afonte dos VOs, sobrevém das exigências da organização e do indivíduo, refletindo suas necessidades biológicas (indivíduo), de sobrevivência (organização e indivíduo) e de bem-estar (indivíduo), as quais 
demandam estratégias organizacionais que norteiam o comportamento dos indivíduos. Logo, se os VOs são introduzidos nas organizações pelas pessoas, elas são a fonte deles. Quando as necessidades dos trabalhadores são atendidas, há felicidade para eles, pois há a crença de que grande parte da felicidade de uma pessoa advém do ambiente de trabalho. Portanto, se estão felizes, implica facilidade na consecução das metas organizacionais (TAMAYO, 2005; TAMAYO; GONDIM, 1996; TAMAYO; MENDES; PAZ, 2000).

Em se tratando do objetivo dos VOs, concentram-se em resolver três problemas: a) conciliação dos interesses individuais e coletivos; b) elaboração de estrutura que contemple normas, papéis e regras para a relação e organizações do trabalho, e c) conciliação entre os interesses das organizações e do meio que a circunvizinha (TAMAYO, 1996).

Valores organizacionais e individuais não são equivalentes, pois enquanto os últimos referenciam metas pessoais e servem como princípio em suas vidas, os primeiros ditam a percepção dos trabalhadores acerca das características da organização. Logo, é uma falácia determinar que os valores organizacionais correspondem ao somatório das metas e finalidades individuais (TAMAYO, 2007; TAMAYO; GONDIM, 1996). A partir desse entendimento, buscou-se criar ferramentas capazes de mensurar os VOs. Nesse sentido, Álvaro Tamayo e colaboradores elaboraram escalas para a captura das percepções dos trabalhadores acerca das características das organizações.

\subsubsection{Escalas de mensuração dos valores organizacionais}

Álvaro Tamayo e colaboradores, entre o final dos anos de1990 e 2004, desenvolveram três escalas para mensuração dos valores organizacionais: Escala de Valores Organizacionais - EVO (1996), o Inventário de Valores Organizacionais - IVO (2000) e o Inventário de Perfis de Valores Organizacionais - IPVO(2004). Em virtude do pioneirismo nacional em estudo sobre o tema, esses autores tornaram-se referência, assim como suas escalas (MELO; DOMENICO,2012).

O IPVO (quadro 2) surgiu do entendimento de que os valores organizacionais possuem uma similaridade motivacional com os valores pessoais. Diante disso, os autores consideraram que a origem, função e componentes motivacionais de ambos eram semelhantes, mas não implicava terem o mesmo significado (OLIVEIRA; TAMAYO, 2004).

Quadro 2 - Inventário de Perfis dos Valores Organizacionais (IPVO)

\begin{tabular}{|l|l|}
\hline Valores Organizacionais & O que mensura? \\
\hline Realização & Competência da organização e dos trabalhadores para alcançar sucesso \\
\hline Conformidade & Respeito à regras e modelos de comportamentos \\
\hline \multicolumn{2}{|l|}{ (Continuação) } \\
\hline Domínio & Obter lucro, ser competitiva e dominar mercado \\
\hline Bem-estar & Promoção do bem-estar dos trabalhadores \\
\hline Tradição & Preservação e respeito aos costumes \\
\hline Prestígio organizacional & Capacidade de Ser conhecida, admirada por todos \\
\hline Autonomia & Capacidade de estimular os trabalhadores para a criatividade e inovação \\
\hline $\begin{array}{l}\text { Preocupação com a } \\
\text { coletividade }\end{array}$ & Promoção de: justiça, igualdade, tolerância, sinceridade e honestidade \\
\hline
\end{tabular}

Fonte: Oliveira e Tamayo (2004).

\section{Método}

De cunho quantitativo e descritivo, esta pesquisa levantou dados utilizando um questionário estruturado com 113 questões (de dados sociodemográficas, valores organizacionais e práticas de espiritualidade), com distribuição por e-mail durante o mês de janeiro de 2016, tendo como respondentes jovens trabalhadores brasileiros pertencentes ao programa Jovem Aprendiz, com idade entre 18 e 24 
anos. Foram obtidos 406 questionários válidos, sendo 99\% dos respondentes da pesquisa oriundos das instituições: SENAC (BA), ISBET (DF) e ISBET (BA).

As variáveis estudadas foram as práticas de espiritualidade (BEZERRA, OLIVEIRA,2007) e os valores organizacionais, descritos pelo IPVO (OLIVEIRA; TAMAYO,2004). Para análise dos dados, foi utilizado o software Statistical Package for the Social Sciences - SPSS Statistics, 23.0. As estatísticas exploratórias e descritivas, bem como a criação dos gráficos de dispersão e a análise das relações entre as variáveis, foram realizadas através da matriz de correlações de Spearman, adotando o seguinte parâmetro: se rho $\geq 0,7$ implica forte relação de magnitude; se $0,4<$ rho $<0,7$ implica moderada relação de magnitude; e se rho $<0,4$ implica fraca relação de magnitude. A escolha do coeficiente de Spearman deu-se por ser o mais adequado para análise de escalas ordinais.

\section{Resultados}

No que tange ao perfil dos respondentes, o gênero feminino foi maioria (67\%). Em termos de idade, notou-se que $65,5 \%$ dos pesquisados tinham entre 18 a 20 anos de idade, sendo que $70 \%$ foram mulheres. Quanto ao estado civil, $90 \%$ declararam-se solteiros. A cor de pele que prevaleceu foi negro ou pardo, com $70 \%$. Destaca-se ainda que $60 \%$ têm escolaridade de nível médio.

O objetivo deste estudo foi compreender as relações entre as práticas de espiritualidade e os valores organizacionais, com o intuito de responder a pergunta de partida, que se pautou em saber: Como as práticas de espiritualidade se relacionam com os valores organizacionais na percepção de jovens trabalhadores? Nesse sentido, o objetivo foi alcançado uma vez que se constatou a existência de relação entre a espiritualidade e os valores organizacionais, diferenciando-os apenas pelo grau de intensidade, sendo apontadas relações variando de fraca, moderada e forte magnitude.

Notou-se ainda que os jovens identificaram, com maior relevância, a presença da prática de espiritualidade relativa à "valorização do funcionário", enquanto que os valores organizacionais mais percebidos em suas organizações foram aqueles relacionados à "realização" e "conformidade" que expressam, respectivamente, a competência da organização e dos funcionários na direção do sucesso, e o respeito às regras e modelos de comportamento.

Quanto à questão de partida, a matriz de correlações de Spearman identificou a existência de 32 relações entre as práticas de espiritualidade e os valores organizacionais, sendo $6 \mathrm{com}$ forte magnitude (rho $\geq 0,7), 20$ com moderada magnitude $(0,4<$ rho $<0,7)$ e outras 6 com fraca relação de magnitude entre si $($ rho < 0,4). Desses dados, percebe-se que a maioria das relações estabelecidas $(62 \%)$ foram moderadas, enquanto as relações de fraca e forte magnitude representaram, cada uma, 19\%. Para esta investigação, apenas as relações com forte associação foram explanadas.

As relações que apresentaram forte magnitude foram distribuídas entre as seguintes variáveis: diminuição da carga de trabalho e bem-estar ( $r h o=0,708$ ); exercício da espiritualidade com bem-estar (rho $=0,777$ ) e autonomia (rho $=0,709$ ); valorização do funcionário com bem-estar (rho $=0,738$ ), autonomia $($ rho $=0,750)$ e preocupação com a coletividade $($ rho $=0,743)$ (tabela 01$)$. 
Tabela 01 - Relações entre práticas de espiritualidade e valores organizacionais

\begin{tabular}{|c|c|c|c|c|}
\hline Valores organizacionais & $\begin{array}{c}\text { Diminuição } \\
\text { carga de } \\
\text { trabalho }\end{array}$ & $\begin{array}{l}\text { Exercício da } \\
\text { espiritualidade }\end{array}$ & $\begin{array}{c}\text { Valorização } \\
\text { do } \\
\text { funcionário }\end{array}$ & $\begin{array}{l}\text { Diminuição } \\
\text { da } \\
\text { competição } \\
\text { interna }\end{array}$ \\
\hline Realização &, $503^{* *}$ &, $565^{\star *}$ &, $688^{* *}$ &, $535^{\star \star}$ \\
\hline Conformidade &, $321^{* *}$ &, $392^{* *}$ &, $607^{* *}$ &, $420 * *$ \\
\hline Domínio & $270^{* *}$ & $371^{* *}$ &, $418^{* *}$ & $306^{* *}$ \\
\hline Bem-estar &, $708^{* *}$ &, $777^{* *}$ &, $738^{* *}$ & $613^{* *}$ \\
\hline Tradição & $376^{* *}$ & $452^{* *}$ & $420^{* *}$ &, $434^{* *}$ \\
\hline Prestígio &, $423^{* *}$ &, $534^{* *}$ &, $591^{* *}$ &, $508^{* *}$ \\
\hline Autonomia &, $618^{* *}$ & ,709** & ,750** & $618^{* *}$ \\
\hline Preocupação com a coletividade &, $564^{* *}$ & ,644** & ,743** &, $584^{* *}$ \\
\hline $\begin{array}{l}\text { **. A correlação é significativa no nível } 0,01 \\
\text { (bilateral). }\end{array}$ & & & & \\
\hline
\end{tabular}

Fonte: Dados da pesquisa (2016).

O esquema teórico, representado pela figura1, tem o intuito de reforçar o entendimento acerca da intensidade da força das relações estabelecidas entre as práticas de espiritualidade e os valores organizacionais a partir da detecção dos coeficientes de correlação de Spearman expressos na matriz de correlações.

Figura 1- Representação das relações entre as variáveis

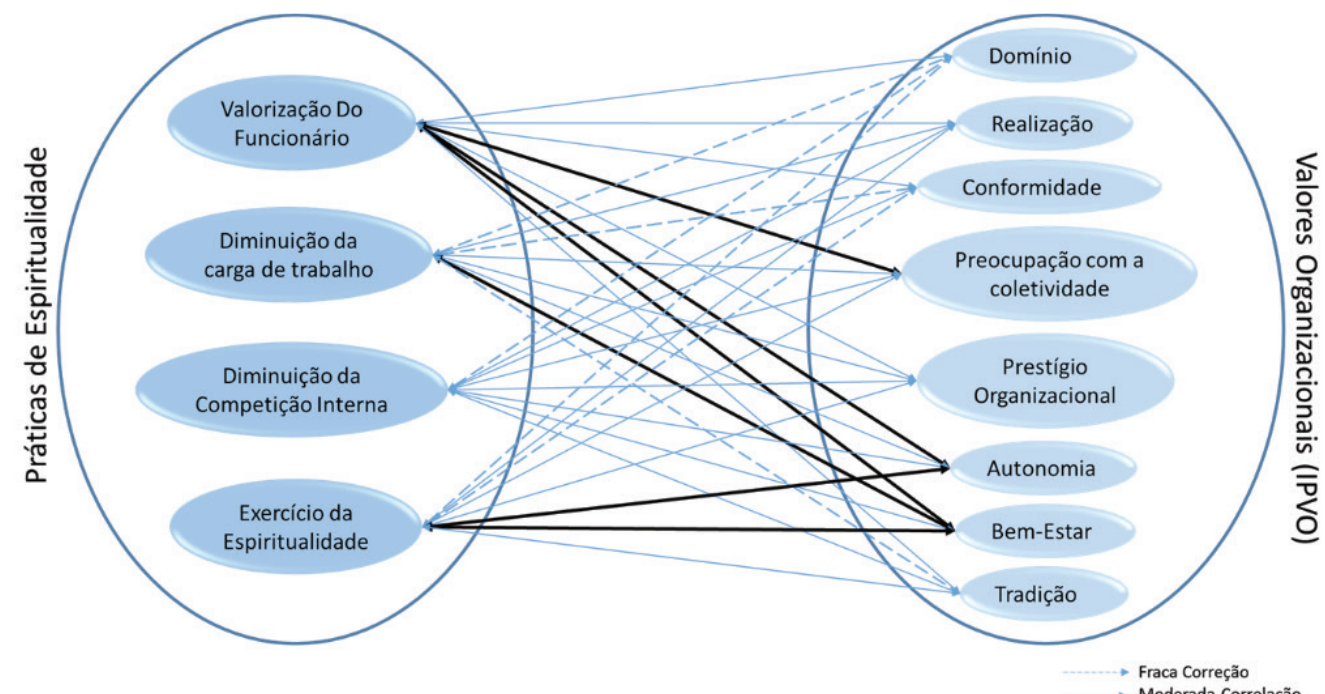

Fonte: Dados da Pesquisa (2016).

A forte associação entre a prática de espiritualidade "diminuição da carga de trabalho" e o VO "bemestar" (gráfico 1), denota a percepção dos jovens trabalhadores acerca da satisfação e qualidade de vida no trabalho (OLIVEIRA; TAMAYO, 2004). Essa associação pode ser oriunda da redução da carga de trabalho, pois se a organização reduz o estresse e cansaço do trabalhador, destinando tempo para relaxamento, meditação e ações comunitárias, pode contribuir para nutrir a vida espiritual do trabalhador, podendo, inclusive, reduzir incidências de bournout em seus ambientes (AJALA ,2013; BEZERRA; OLIVEIRA,2007) 
Gráfico 1 - Diminuição da carga de trabalho X Bem-estar

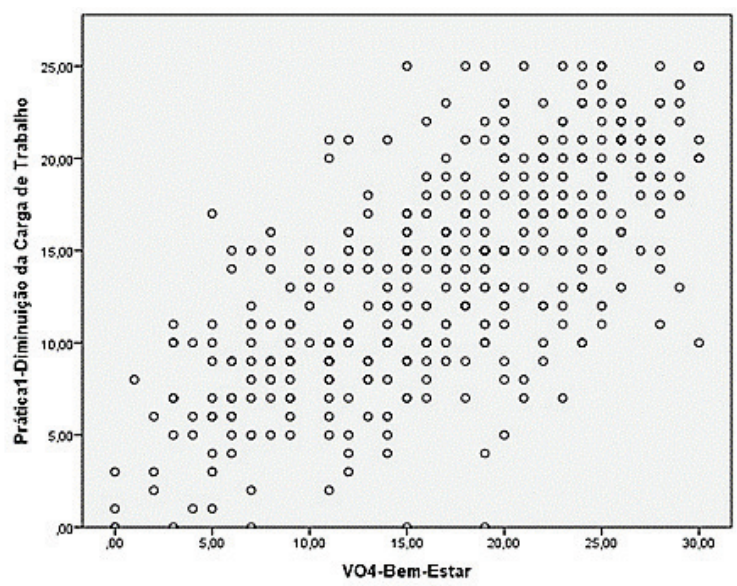

Fonte: Dados da pesquisa (2016).

A prática do "exercício da espiritualidade" apresenta forte relação de magnitude com os valores organizacionais "bem-estar" e "autonomia". Quanto ao primeiro valor (bem-estar), é possível que, ao passo que a organização promova a postura ética, prática dos valores universais, qualidade de vida, incentivo à meditação, e a promoção de treinamentos e cursos para difundir os conceitos da espiritualidade, gere no indivíduo uma sensação de "bem-estar", garantindo satisfação e qualidade de vida a ele, fato também visto nos achados de Dihiman e Marques (2010), os quais afirmaram que ações com cunho espiritual adotadas por organizações tendem a elevar o bem-estar organizacional (gráfico 2).

Na relação entre o "exercício da espiritualidade e a "autonomia" (estímulo à criatividade, curiosidade e inovação), nota-se que há chances de que, ao incentivar que o indivíduo exercite a espiritualidade pela adoção de uma postura ética (exercício da espiritualidade) esses trabalhadores consigam designar as suas tarefas, curiosidade, criatividade e inovação, resultado também relatado nos estudos de Mitroff e Denton (1999), que encontraram evidências de organizações que possuem espiritualidade com base em critérios éticos, tendendo a permitir que seus funcionários tenham ambientes permeados de criatividade e flexibilidade (gráfico3).

Gráfico 2- Exercício da espiritualidade X Bem-estar

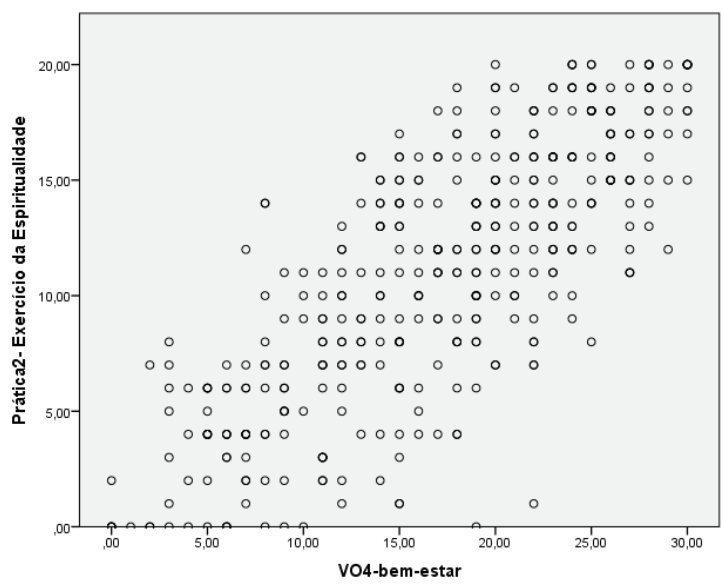

Fonte: Dados da pesquisa (2016).

\section{Gráfico 3- Exercício da espiritualidade X Autonomia}

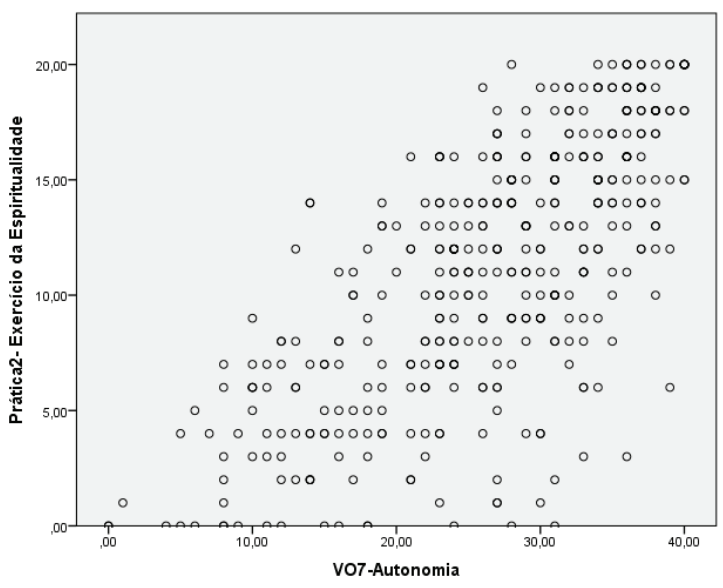

Fonte: Dados da pesquisa (2016). 
A prática de espiritualidade relativa à "valorização do funcionário" apresentou forte associação com os valores organizacionais atinentes ao "bem-estar", "autonomia" e "preocupação com a coletividade". Na primeira relação, valorização do funcionário versus bem-estar (gráfico 4), a percepção do jovem é a de que ele pode experimentar a sensação de bem-estar quando a organização respeita suas necessidades emocionais, valoriza suas dimensões intelectuais e emocionais, motiva-os, trata a todos com dignidade, reduz as pressões para o alcance das metas e reconhece seus esforços. Logo, o bem-estar, a satisfação nas tarefas e a qualidade de vida são consequências oriundas das práticas de espiritualidade que versam no sentido de respeitar e valorizar os indivíduos, não apenas como meros corpos e mentes, mas também como seres dotados de coração, espírito, criatividade e talentos (AJALA, 2013).

Na segunda forte relação estabelecida, entre a prática de espiritualidade "valorização do funcionário" e o valor organizacional "autonomia", os jovens percebem que se a organização adotar práticas de espiritualidade no sentido de valorizar o funcionário, baseando-se na redução das pressões para o alcance das metas, ela poderá estimular o indivíduo a enfrentar novos desafios, desenvolvendo a sua autodeterminação e contribuindo para a realização das atividades com curiosidade, criatividade e inovação, pois o que "molda as ações dos indivíduos é a espiritualidade" (AJALA, 2013, p.8) (gráfico 5).

Gráfico 4 - Valorização do funcionário X Bem-estar

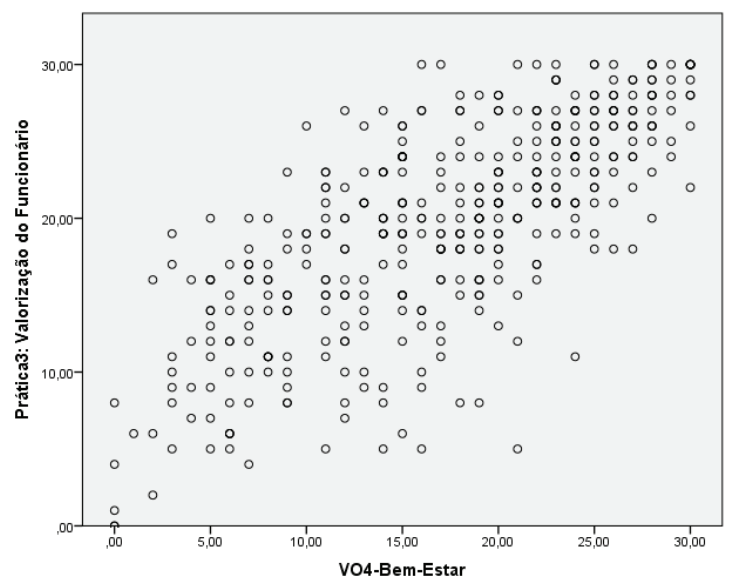

Fonte: Dados da pesquisa (2016).
Gráfico 5 - Valorização do funcionário XAutonomia

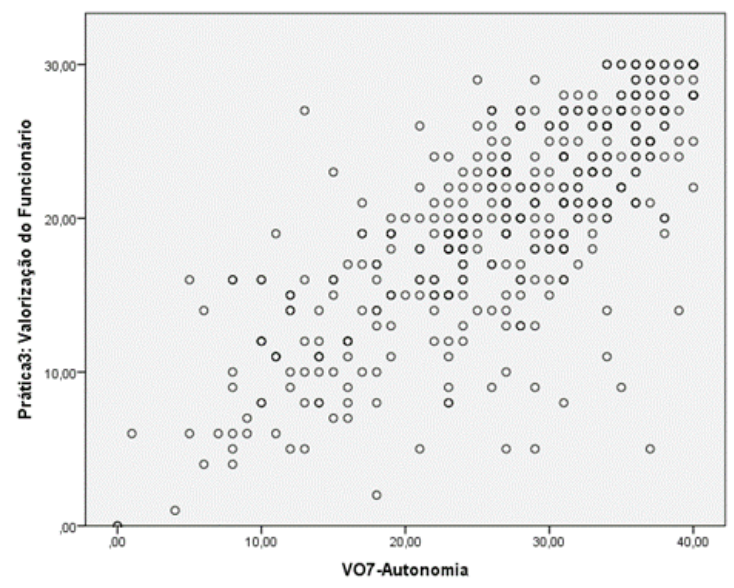

Fonte: Dados da pesquisa (2016).

Por fim, em se tratando do valor organizacional "preocupação com a coletividade", que mensura a capacidade da organização em promover justiça, igualdade, tolerância, sinceridade e honestidade em seu ambiente, percebe-se forte relação de magnitude com a prática de espiritualidade "valorização do funcionário", que implica o entendimento de que se a organização praticar ações no sentido de valorizar o funcionário, por intermédio dos seus valores morais, e não apenas com vistas às metas alcançadas, é possível que ela contribua para que o funcionário perceba nos seus atos os valores relativos à preocupação com a coletividade (benevolência e universalismo), porque, de acordo com Ajala (2013), a espiritualidade é um potencial contribuinte para nutrir conexões humanas e elevar o nível de desenvolvimento comunitário no local de trabalho (gráfico 6). 


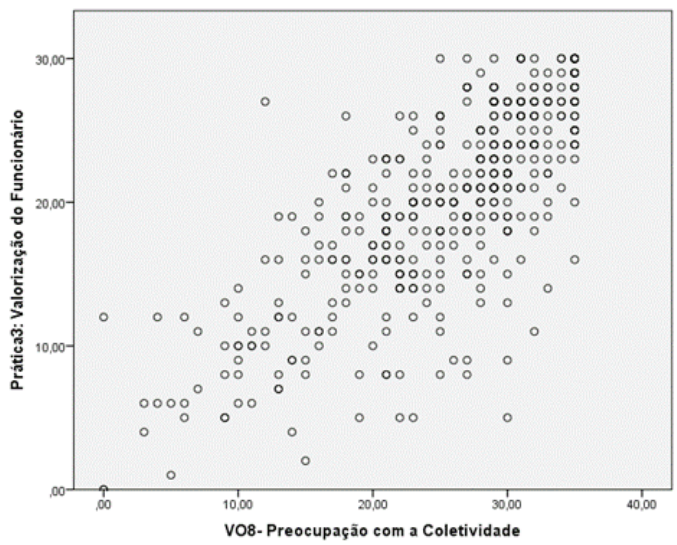

Fonte: Dados da pesquisa (2016).

Assim sendo, das quatro práticas de espiritualidade sugeridas, identificou-se que apenas uma delas - "diminuição da competição interna" - não apresenta relação de forte magnitude com os valores organizacionais listados, apesar de estabelecer relação positiva com todos.

\section{Conclusão}

Este estudo buscou verificar as relações entre as práticas de espiritualidade e os valores organizacionais, a partir da percepção de jovens trabalhadores brasileiros, utilizando a análise quantitativa pela matriz de correlações de Pearson. Dessa análise, constatou-se que há relação entre as variáveis do estudo. Além disso, percebeu-se também que os valores organizacionais que obtiveram relação mais evidente com as práticas de espiritualidade foram "bem-estar", "preocupação com a coletividade" e "autonomia". Os dados demonstraram que, quando a organização adota como prática a "diminuição da carga de trabalho", investindo na redução do estresse, na disponibilização de tempo para ações comunitárias, relaxamento e meditação, os indivíduos tendem a experimentar a sensação de bem-estar em seus ambientes laborais.

Outra confirmação trazida pelo estudo diz respeito ao fato de que a organização proporciona o bemestar, assim como traz estímulo à criatividade e inovação para os funcionários, quando adota práticas concernentes ao "exercício da espiritualidade" a partir da difusão e prática de conceitos da espiritualidade por intermédio de palestras e cursos voltados para: a) trabalho em equipe; b) alinhamento dos valores organizacionais e individuais; c) alegria no trabalho; d) desenvolvimento da pessoa como ser humano; e e) ações comunitárias, além de proporcionar ao trabalhador qualidade de vida e promoção dos valores universais.

Por fim, ao praticar ações no sentido de "valorização do funcionário", concedendo-lhe: tratamento digno e respeitoso; reconhecimento de suas ações e emoções; investimento na sua motivação; e redução das pressões para o alcance das metas, observa-se que o funcionário tende a perceber no ambiente as metas relativas aos valores organizacionais referentes ao "bem-estar", "autonomia", e preocupação com a coletividade, que expressam, respectivamente, a promoção da sensação de bem-estar, o estímulo à inovação, criatividade, promoção da justiça, igualdade, tolerância, sinceridade e honestidade.

A prática de espiritualidade "diminuição da competição interna", representada por ações que envolvem a promoção do companheirismo entre os colegas e o desestímulo à competição, apresentou relação de menor intensidade que as demais práticas com os valores organizacionais relativos ao bemestar e estímulo a inovação e criatividade (autonomia). Ainda referente a essa prática, identificou-se baixa correlação entre "diminuição da carga de trabalho" e os valores organizacionais relativos a: "prestígio organizacional"; "conformidade de padrões e regras" e "domínio do mercado". Tal fato pode ser explicado em virtude de que esses valores podem demandar maior esforço do trabalhador e consequentemente aumentar a carga de trabalho, haja vista que eles descrevem o desejo da organização em ganhar novos 
mercados, além da admiração e respeito dos clientes devido à qualidade de seus produtos, e ainda por pensar que o "trabalhador deve aceitar o trabalho que tem a fazer".

Portanto, conclui-se que há forte relação de magnitude entre as práticas de espiritualidade "diminuição da carga de trabalho", "valorização do funcionário" e "exercício da espiritualidade" com os valores organizacionais "autonomia", "bem-estar" e "preocupação com a coletividade". Dessa relação ainda se pressupõe que as práticas listadas podem ser preditoras da percepção dos valores organizacionais por parte dos trabalhadores, uma vez que, ao implantar essas práticas de espiritualidade, a organização contribuirá para que o funcionário perceba essas ações como promotoras de satisfação (bem-estar), estímulo à criatividade e inovação (autonomia), assim como justiça, igualdade, tolerância, sinceridade e honestidade (preocupação com a coletividade).

\section{Referências}

ALMEIDA, F. J. R.; SOBRAL, F. J. B. A. O sistema de valores humanos de administradores Brasileiros: adaptação da escala PVQ para o estudo de valores no Brasil.RAM, Rev. Adm. Mackenzie, São Paulo, v.10, n. 3, p. 101-126, Jun. 2009.

AJALA, E. M. The impact of workplace spirituality and employees'wellbeing at the industrial sector: the nigerian experience. Journal of the African Educational Research Network, [S.I], v. 13, n. 2, p. 1-13, 2013.

AKTOUF, O.. A administração entre a tradição e a renovação. Organização, adaptação e revisão Tradução: Roberto Fachin e Tânia Fischer. São Paulo: Atlas, 2010.

ASHMOS, D.P.; DUCHON, D. Spirituality at work: A conceptualization and measure.Journal of Management Inquiry,[S.I], v. 9, n. 2, p. 134-145, 2000.

BEZERRA, M. F. N.; OLIVEIRA, L. M.B.. Espiritualidade nas Organizações e Comprometimento Organizacional. Estudo de Caso com um Grupo de Líderes de Agências do Banco do Brasil na cidade de Recife. In: ENCONTRO DA ASSOCIAÇÃO NACIONAL DE PÓS-GRADUAÇÃO EM ADMINISTRAÇÃO, 31., 2007. Rio de Janeiro. Anais... Rio de Janeiro: ANPAD, p. 1-14, 2007.

CHANLAT, J. F. Por uma Antropologia da condição humana nas organizações. In: CHANLAT, J. F. (Coord.). $\mathbf{O}$ indivíduo na organização: dimensões esquecidas. Tradução de Ofélia de Lanna Sette Tôrres. 3. ed. São Paulo: Atlas, v. 1, p. 1-6, 1996.

DE MASI, D. O futuro do trabalho: fadiga e ócio na sociedade pós-industrial. Tradução de Yadyr A. Figueiredo. 7. ed. Rio de Janeiro: José Olympio, 2001.

DEJOURS, C. Subjetividade, trabalho e ação. Production,São Paulo, v. 14, n. 3, p. 27-34, dez. 2004. Disponível em: <http://www.scielo.br/scielo.php?script=sci_arttext\&pid=\$0103-65132004000300004\&lng =en\&nrm=iso>. Acesso em: 07 abr. 2015

DHIMAN, S.; MARQUES, J. The role and need of offering workshops and courses onworkplace spirituality, Journal of Management Development, [S.I], v. 30, n. 9, p. 816 - 835, 2011.

FARIA, J. H.; SCHMITT, E. C. Indivíduo, vínculo e subjetividade: o controle social a serviço das organizações. In: ENEO, 3., 2004, Atibaia. Anais... Atibaia - SP: ENEO, 2004, p. 1-16.

FLEURY, M. T. L..O desvendar a cultura de uma organização: uma discussão metodológica. In: FLEURY, M. T. L. FISCHER, R. M. (Org.). Cultura e poder nas organizações. 2. Ed. São Paulo: Atlas, 1996. p.15-27.

FRESHMAN, B. An exploratory analysis of definitions and applications of spirituality in the workplace. Journal of Organizational Change Management, [S.I], v.12, n.4, p.318- 327, 1999.

FRY, L. W. Toward a theory of spiritual leadership. The Leadership Quarterly, [S.I], v. 14, p. 693-727, 2003. 
GIACALONE, R. A.; JURKIEWICZ, C. L. Toward a science of workplace spirituality. In: GIACALONE R. A e. JURKIEWICZ C. L (Eds.), The Handbook of Workplace Spirituality and Organizational Performance. Armonk, NY: M. E. Sharpe, p. 1-26, 2003.

KARAKAS, F.Spirituality and performance in organizations: a literature review. Journal of Business Ethics,[S,I], v. 94, n. 1, p. 89-106, 2010.

KAUANUI, K.S. et al. Entrepreneurship and spirituality: a comparative analysis of entrepreneurs' motivation. Journal of Small Business \& Entrepreneurship, [S.I], v. 23, p. 621-635, 2010

LAZZARESCHI, N. Trabalho ou emprego? 1.ed. São Paulo: Paulus, 2007. 96 p. (Coleção Questões Fundamentais do Ser Humano, 6).

LEFEBVRE, S.La crise du croire em enterprise et la necessite d'um dialogue sur la signification du travail. In: PAUCHANT, T.et associés: Pour un management éthique et spirituel, Défis, cas, outils et questions, Montréal, Fides et Presses HEC, 2000, p. 67-78.

LOUBACK, J.; TEIXEIRA, M. L. M.; BIDO, D. S. Valores organizacionais e racionalidades: uma visita ao terceiro setor. Organizações \& Sociedade, [S.I], v. 16, n. 49, art. 2, p. 225-246, 2009

MELO, W. F.; DOMENICO, S. M. R. A Influência dos Valores Organizacionais no Desempenho de Agências Bancárias. Rev.Adm. Contemp., [S.I], v. 16, n. 1, p. 137-156, 2012.

MILLIMAN, J.; CZAPLEWSKI, A. J.; FERGUSON, J. Workplace spirituality and employee work attitudes: An exploratory empirical assessment. Journal of Organizational Change Management, [S.I], v. 16, n. 4, p. 426-447, 2003.

MITROFF, I. I.; DENTON, E. A. A study of spirituality in the workplace. Sloan Management Review, [S.I], v 40, n.4, p. 83-92, 1999.

MITROFF.I. La spiritualité au travail: le prochain défi majeur em management. In: PAUCHANT, T.et associés: Pour un management éthique et spirituel, Défis, cas, outils et questions, Montréal: Fides et Presses HEC, 2000. p. 67-78

MORIN, E. M. Os sentidos do trabalho. Rev. Adm. Empres., São Paulo, v. 41, n. 3, p. 8-19, set. 2001. Disponível em: <http ://www.scielo.br/scielo.php?script=sci_arttext\&pid=S0034$75902001000300002 \&$ Ing $=$ pt\&nrm $=$ iso $>$. Acesso em: 2 jul. 2015.

NEAL, J. Assessing Workplace Spirituality. In: NEAL, J. Creating Enlightened Organizations: Four Gateways to Spirit at Work. New York: Palgrave Macmillan US. 2013. p.121-136

OIT. Perfil do trabalho decente no Brasil. 1.ed.Brasília; Genebra: Escritório da Organização Internacional do Trabalho, 2009. 74 p.

OLIVEIRA, A.; TAMAYO, A. Inventário de perfis de valores organizacionais. Revista de Administração da Universidade de São Paulo, São Paulo, v. 369, n. 2, p. 129-140, abr./jun. 2004

ORNELLAS, T.C.F.; MONTEIRO, M.I. Aspectos históricos, culturais e sociais do trabalho.

Revista Brasileira de Enfermagem, v. 59, n. 4, p. 552-555, ago. 2006,

PANAHI, B.;ABEDINPOOR,A.Identification of spiritual organizations: theories and models. 2012.

Disponível em: <www.wbiconpro.com/721-Panahi.pdf>Acesso em: 13 jan. 2016.

PAUCHANT, T. et al. Le Mangement èthique et spirituel répond à un besoin de sens au travail. In: PAUCHANT, T. Pour un management éthique et spirituel,. Défis, cas, outils et questions. Montréal: Fides et Presses HEC, 2000.p. 13-46

RAMOS, G. Uma introdução ao histórico da organização racional do trabalho. 1.ed. Brasília: Conselho Federal de Administração, 2008.

REGATIERI, T. L.; MORAES, R. M.; JOST, R. C. F.; SOBOLL, L. A. P.; FARIA, J. H. 
Sequestro da subjetividade e o programa de trainee nas melhores empresas para se trabalhar. In: Jornada Internacional de Práticas Clínicas no Campo Social, I, 2010, Maringá. Anais...

Maringá: UEM, 2010.

REGO, A.; CUNHA, M. P. ; SOUTO, S. Espiritualidade nas organizações e comprometimento organizacional. RAE electron., São Paulo, v. 6, n. 2, Dez. 2007. Disponível em: <http://www.scielo.br/ scielo.php?script=sci_arttext\&pid=S1676-56482007000200003\&Ing=en\&nrm= isso >. Acesso em: 22 out. 2015.

SOUTO, S. O., REGO, J. A. Espiritualidade nas organizações, positividade e desempenho. In: In: ENCONTRO DA ASSOCIAÇÃO NACIONAL DE PÓS-GRADUAÇÃO EM ADMINISTRAÇÃO, 30., 2006, Salvador. Anais... Salvador: Anpad, p. 1-16, 2006.

SCHWARTZ, S.H. Are there universal aspects in the content and structure of values?Journal of Social Issues, [S.I], v. 50, p. 19-45, 1994

SENNETT, Richard, 1943- A corrosão do caráter: as consequências pessoais do trabalho no novo capitalismo. $14^{\mathrm{a}}$ ed. - Rio de Janeiro: Record, 2009. Tradução Marcos Santarrita.

TAMAYO, A. Valores Organizacionais: sua relação com satisfação no trabalho, cidadania organizacional r comprometimento afetivo. Revista de Administração, São Paulo v. 33,n.3, p.56-63, jul./set. 1998.

TAMAYO, A.Valores organizacionais. In: TAMAYO, A.; BORGES-ANDRADE, J. E.; CODO, W. (Org): Trabalho, organizações e cultura. Rio de Janeiro: Associação Nacional de Pesquisa e Pós-graduação em Psicologia. p. 157-172(Coletâneas da Anpepp no. 11).

TAMAYO, A.; GONDIM, M.G.C. Escala de Valores Organizacionais. Revista de Administração da USP, São Paulo, v.31, n.2, p. 62-72, abr./jun. 1996

TAMAYO, A.; MENDES, A. M.; PAZ, M.G. T. Inventário de valores organizacionais. Estudos de Psicologia (Natal), Natal, v. 5, n. 2, p. 289-315, dez. 2000. Disponível em <http://www.scielo.br/pdf/ epsic/v5n2/a02v05n2.pdf >. Acesso em 02 set. 2015.

TAMAYO, A.;SCHWARTZ, S.H. Estrutura motivacional dos valores. Psicologia: Teoria e Pesquisa, [S.I], v.9, n.2, p. 329-348, 1993.

TAMAYO, A. Valores organizacionais e comprometimento afetivo. Revista De Administração Mackenzie,[S.I], Ano 6, n.3, p.192-213,2005.

VASCONCELOS, A. F. Qualidade de vida no trabalho: origem, evolução e perspectivas. Caderno de Pesquisas em Administração, São Paulo, v.8, n.1, jan./mar. 2001. Disponível em: <http://www.ead.fea. usp.br/cad-pesq/arquivos/v08-1art03.pdf>. Acesso em: 20 set. 2015.

VERGARA, S. C.; MOURA, L. S. Práticas de espiritualidade na gestão de pessoas. In: ENCONTRO DA ASSOCIAÇÃO NACIONAL DE PÓS-GRADUAÇÃO E PESQUISA EM ADMINISTRAÇÃO, 36., 2012, Rio de Janeiro. Anais... Rio de Janeiro: ANPAD, p. 1-14, 2012.

WEIL, S.L'enracinement. Prélude à une déclaration des devoirs envers l'être humain. Paris: Les Éditions Gallimard, 1949, 381 p. Collection idées.

ZOHAR, D.; MARSHALL, I. Inteligencia Espiritual, la inteligencia que permite ser creativo tener valores y fe. 1. ed. Barcelona: Plaza \& Janes, 2001.Traducción: Marcelo Convián.

Data de Submissão: 29/1/17

Data de Aprovação: 9/4/17 